\title{
On Establishing the Writer's Credibility in Persuasive Writing
}

\author{
Yuru Shen \\ School of Foreign Languages, Leshan Normal University, No. 778, Binhe Road, Leshan, Sichuan, 614004, China
}

\begin{abstract}
Persuasive writing, also known as creative writing, or an argument, or "an essay that offers and supports an opinion," is one of the most frequently used writing types in our life and work. It usually begins with "identity" between the writer and the audience and ends in the audience's changing their mind or bringing their viewpoints closer to the writer's. Whether a piece of writing is persuasive or not depends on a variety of factors, but the writer's credibility is a very important factor that cannot be ignored. So this essay will mainly discuss how a writer's credibility contributes to the persuasiveness of his/her writing and how to establish his/her credibility.
\end{abstract}

Index Terms - credibility, persuasive writing, emotionally, reasonably, accommodate, establish

\section{INTRODUCTION}

Persuasive writing, also known as creative writing, or an argument, or "an essay that offers and supports an opinion" (http://en.wikipedia.org/wiki/ Persuasive_writing), is one of the most frequently used writing types in our life and work. It seeks to convince the audience to adopt the writer's point of view or to do something through a strong voice, the writer's conviction, or the vivid examples and illustrations employed to support the stated position. So persuasive writing usually follows this pattern: beginning with "identity" between the writer and the audience and ending in the audience's changing their mind or bringing their viewpoints closer to the writer's. But more often than not, we find that one piece of writing may be more persuasive than another, even if both follow the same pattern. Then what makes the audience accept one writer's views rather than those of another?

Undoubtedly, a variety of factors, such as how interesting the topic is, how the writer uses words, and phrases--appropriately, exactly and idiomatically?, how the writer arranges the sentences, and how credible the writer is, determine whether a piece of writing is persuasive or not. But of the so many factors, the writer's credibility is a key factor that cannot be ignored. In fact, it can be said without any exaggeration that credibility is the cornerstone of effective persuasion, or in other words, the persuasiveness of a piece of writing depends to a great extent on the writer's credibility.

Then what is credibility? Why and how should a writer establish his/her credibility? These questions will be answered in the following, with special emphasis on the strategies for establishing a writer's credibility.

\section{CRedibility ANd Persuasive Writing}

"Credibility," which traces back to Aristotle, who coined the term "ethos" to describe qualities of the source that facilitated persuasion, refers to the degree to which the audience considers the writer believable, or simply put, what the audience thinks of the writer. It includes three core dimensions: expertise, which refers to the knowledge or ability ascribed to the writer; trustworthiness, which refers to the writer's perceived honesty, character, and safety; goodwill, which means that the writer has the audience's benefit at heart, shows understanding of others' ideas, and is empathic toward his or her audience's problems. Generally speaking, a writer perceived as an individual of integrity and character, and with rich knowledge and goodwill is more credible and therefore, more likely to work wonders in persuasion, gaining the audience's trust and inspiring them.

Just as a speaker may have high credibility for one audience and low credibility for another and may also have high credibility on one topic and low credibility on another, a writer's credibility can also be strengthened or weakened by his/her message and how he/she delivers it. If the audiences consider the writer sincere and competent, they will be much more receptive to his/her ideas and are more likely to change their attitudes or to do something.

Since the audiences are more likely to trust those who have personal warmth, consideration of others, a good mind and solid learning, to trust those with whom they share convictions about what is right and wrong, and to trust those who are sincere in purpose, well-informed about a particular subject and fair in arguing, it is fairly necessary for us writers to try every possible means to make ourselves appear capable and trustworthy. Specifically, we can employ the following strategies to establish and enhance our credibility.

\section{STRATEGIES FOR ESTABLISHING THE WriteR’s CREDIBILITY}

\section{A. Demonstrating Our Competence}


The more knowledgeable the audiences perceive a writer to be, the more likely and more willing they are to believe him/her. To demonstrate our competence, besides telling our audience of a special experience or training that qualifies us to write on a particular topic, and showing them that we have thoroughly researched the topic by citing a variety of research sources, we also need to do the following.

1. Presenting our ideas vividly

It is a common sense that in speaking we often take advantage of the audience's senses (vision, hearing, taste, smell and touch) to help express ourselves clearly. For instance, if we are describing the odor of an object, we may let the audience smell it; if we are describing a kind of food, we may let them taste it. Similarly, in writing we can also appeal to the audience's senses by using specific and concrete words and phrases or by providing details or by using figurative language to present word pictures.

On the one hand, employing strong specific and concrete words and phrases instead of general and abstract ones helps present our ideas vividly, because the former are much more informative, expressive and colorful and can help to make our writing so clear, exact, vivid, and striking that they seem to make the reader "see," "hear," or "feel" what we wish to describe. For instance, we may use "the flowers in the vase near the window" instead of "flowers," "Hurricane Katrina" instead of "hurricane," "the brownstone" or "the bungalow" instead of "the house," "pop up like corn" instead of "appear suddenly," "tiptoed to the window" instead of "went to the window" and so on and so forth. In the same way, we may use dynamic rather than static verbs, verbs that help to paint a picture. For example, if we want to describe Joe's anxiety and nervousness when he received a telephone, instead of saying "Joe was worried when the telephone rang," we can write this sentence: "When the phone finally rang, Joe leaped from the edge of his chair and grabbed for it." From such impressive terms of expression as "finally," "leaped from the edge of his chair" and "grabbed for it," the audience can inevitably "see" the anxiety and nervousness on Joe's face and "hear" the ringing of the phone and conjure up a clear picture of the worried Joe.

On the other hand, providing details is also a good way to help present our ideas vividly. For instance, if we intend to tell our audience that it is often windy and dusty here in spring, instead of telling them "it is often windy and dusty here in spring," which is too general a statement that they cannot imagine how windy and dusty it is here in spring, we can provide some details to help them "feel the wind and the fine dust flying here and there." The following group of sentences is a good example: "In spring there is often a very strong northwest wind. It carries so much fine dust with it that sometimes the sun becomes obscure. There is no escape from the fine dust; it gets into your eyes, your ears, your nostrils, and your hair. It goes through the cracks of closed windows and covers your desks and chairs." (Shi Jian, 2010)

Besides, figurative language, which produces pictures or images in the audience's mind, often by comparing something unfamiliar to something familiar, not only can help us present our ideas in clear, concrete, economical ways but also can make our paper more memorable---especially if the image or picture we present is a fresh, arresting one. Suppose we intend to tell the audience how the dust rose under the feet of a team of horses as they ran over a dirty road. Instead of providing a long and detailed description of the rising dust, we may make the following comparison: The yellow dust of the road rose like a cloud under the horses' feet. The phrase "like a cloud" calls up a mental picture which immediately enables the audience to see in their mind's eye the "yellow cloud of dust" boiling up from the road and dancing about the horses' feet. This example well illustrates that using figurative language benefits both the writer and the reader in that the former can take the short cut to paint a clear mental picture quickly and the latter can make sense of what is intended to convey without any difficulty.

However, although figurative language, like any spice, can spice up our paper, it can also be misused, thus spoiling our soup. Generally, too many images or too many stale ones, like "snake in the grass," "as busy as a bee," "quiet as a mouse," "poor as a church mouse," etc., are not desirable because the former will confuse the audience while the latter may bore them. So, only when it is absolutely necessary do we need to employ images, those that can catch our readers' attention with a fresh picture.

In short, whenever we write and whatever we write about, we had better write as specifically as the situation permits so as to appeal to the audience's senses as we do in our speaking as long as we do not overdo it.

2. Presenting our ideas emotionally

To persuade our audience, we may also appeal to their emotions, whose purpose is to make them "feel sad, angry, guilty, afraid, happy, proud, sympathetic, or nostalgic" (Lucas, 1989). By addressing their feelings about the subject, we can put the audience in a suitable mood. Nikos Kazantzakis' "A Night in a Calabrian Village" (qtd. in Yang, 1984) is a good example of using emotion-laden expressions:

The old lady had already risen and placed a saucepan on the fire to prepare the morning milk. I look at her now in the sparse daylight. Shriveled and humped, she could fit in the palm of your hand. Her legs were so swollen that she had to stop at every step and catch her breath. But her eyes, only her large pitch-black eyes, gleamed with youthful, waging brilliance ...

With graphic expressions the writer of the above paragraph hopes to stimulate the audience's emotional reactions, that is, to arouse their sympathy and respect for the young in spirit, but lonely old lady.

However, although emotional appeals often make a writer's feelings and ideas alive, we should never substitute emotional appeals for evidence and reasoning. If we employ too many emotion-laden expressions, the audience's attention can be distracted and as a result, the impact of the whole writing will be undermined. When using emotional 
appeals, we must bear in mind that "the strongest source of emotional power is the conviction and sincerity of the speaker" (Lucas, 1989). It is all right to get our audience to receive our ideas by making them "pleased and friendly" or "pained and hostile," but playing on their emotions in ways that make them mindless of concepts and consequences can corrupt the judgment of both individuals and the community (Henning, 1998). So we had better present our ideas intellectually and emotionally by using appropriate emotion-laden expressions when absolutely necessary.

3. Presenting our ideas with personal integrity

Besides presenting our ideas vividly and emotionally, we should try to employ ethical appeal, that is, to establish a credible persona worthy of respect and attention of the audience by presenting our ideas with integrity. We should try to project an impression to the audience that we are worth listening to, in other words, try to make ourselves as authors into authorities on certain subjects, as well as people who are likable and worthy of respect. To achieve the purpose, we need to do the following.

For one thing, we must show our audience that we are knowledgeable, that we are well informed about the subject in question, that we have experienced what we are talking about, or that we have made an exhaustive study of the subject. For instance, the writer Anna Quindlin (qtd. in Trimmer, 1988) reveals at the very beginning of her essay "Death Penalty's False Promise: An Eye for an Eye" that she is well qualified to talk about the subject "crime and revenge" and that she is quite knowledgeable about this subject. She says,

Ted Bundy and I go back a long way, to a time when there was a series of unsolved murders in Washington State known only as the Ted murders. Like a lot of reporters, I'm something of a crime buff.... But Ted Bundy has made me think about it all over again, now that the outlines of my 60's liberalism have been filled in with a decade as a reporter covering some of the worst back alleys in New York City and three years as a mother who, like most, would lay down her life for her kids. ... The ones I have met in the course of my professional duties have either sneered at the justice system ..., or they have simply believed that it is the other guy who will get caught, get convicted, get the stiffest sentence.

For another, we must show our audience that we have good intentions, that we have considered their interests and needs as well as our own, and that they have more or less influenced our plan. Our intentions can determine the degree of trust and respect our audience will give us. Once the audience suspect that we are supporting a proposal because of the possibility of our profiting from it, they will reject our views without any hesitation. We should never say anything that might cause such suspicion.

What's more, to make our audience believe that we are sincere, honest and trustworthy, and that we are not only truthfully presenting our evidence but also morally upright and dependable so as to elicit positive response from them, we should present facts, figures or other evidence accurately, refute the opposing views fairly, discuss the subject objectively and show them that our viewpoints allow for differences.

Besides the three ways mentioned above, we can employ some other ways to illustrate that we have good character and are reliable, such as using only credible, reliable sources to build our argument and citing those sources properly, acknowledging values and beliefs shared by both parties, and organizing our argument in a logical, easy-to-follow manner.

4. Presenting our ideas reasonably

Lucas (1989) says, "No matter how strong your evidence is, you will not be very persuasive unless listeners grasp your reasoning." It is also true of writing. When we write to convince our audience of something, we are actually trying to change their attitudes, values or behavior. They want some justification for modifying their attitudes or behavior. They want to know "why." To answer the question "why," we must offer statements, which are also called reasons, that provide substantiation or justification. Let's take Charles De Gaulle's speech "Has the Last Word Been Said" (qtd. in Shi Youshan, 1989) for example. To support his proposition that the last word had not been said and that all hope was not lost, De Gaulle gave the following reasons:

For France is not alone. She is not alone! She is not alone! She has a vast empire behind her. She can form a coalition with the British Empire, which holds the sea and is continuing the struggle. She can, like England, have limitless access to the immense industrial power of the United States.

Reason can also be defined as "logical thought" (Young, 1970). Then reasoning is the process of drawing a conclusion based on evidence. There are several methods of reasoning such as deductive reasoning, inductive reasoning, causal reasoning and analogical reasoning, but the most commonly used are deductive and inductive reasoning.

Deductive reasoning, or deduction, moves from a general principle (assumed to be true) to the particular case. It introduces this principle up-front and then uses it to select and interpret evidence. Deduction, also called syllogism, consists of a general premise, a minor premise and a specific conclusion derived from the relationship of the two premises. When using deductive reasoning, we should pay special attention to the general premise and the minor premise. Only when both premises are soundly based will the audiences agree with our conclusion. For instance, in the essay "Death Penalty's False Promise: An Eye for an Eye," the writer Anna Quindlin (qtd. in Trimmer, 1988) advocates that killing a person cruelly be forbidden in a civilized society. To support her proposition, she uses implied deductive reasoning. She first puts forward the general premise that killing a person is cruel and debasing and then presents the minor premise that killing a murderer is killing a person. After that she arrives at her conclusion that killing a murderer as he kills others is cruel and debasing, and hence should be forbidden in a civilized society. She says, 
I don't believe deterrence is what most proponents seek from the death penalty anyhow. Our most profound emotional response is to want criminals to suffer as their victims did. When a man is accused of throwing a child from a high-rise terrace, my emotional—some might say hysterical—response is that he should be given an opportunity to see how endless the seconds are from the 31 st story to the ground. In a civilized society that will never happen. So what many people want from the death penalty, they will never get.

A good deduction is, however, "more than a mechanical application or matching exercise of general claim and specific details that are explained by it" (Rosenwasser \& Stephen, 2008). The general principle and the evidence are reciprocal: the former explains selected features of the latter; the latter brings out implications in the former.

Whereas deduction moves by applying a generalization to particular cases, induction moves from the observation of individual cases to the formation of a general principle. Because all possible cases can obviously never be examined, the principle (or thesis) arrived at through inductive reasoning always remains open to doubt.

Nevertheless, the thesis of an inductive paper is "generally deemed acceptable if a writer can demonstrate that the theory is based on a reasonably sized sampling of representative instances" (Rosenwasser \& Stephen, 2008). Suppose we find that our company is losing many valuable computer operators to other companies and we wonder why. After making surveys, we find the following main pieces of evidence: most computer operators are women who have preschool children; a nearby day-care center used by employees has closed because it lost funding from the local government; other day-care centers in the area are inconvenient and understaffed; other companies provide on-site day care for children of employees; on-site day care is beneficial to the emotional well-being of both preschool children and their mothers, because of the possibility of contact during the workday. With the evidence comes our conclusion, which seems warranted by the evidence we have collected: Therefore, our company needs to provide on-site day care to retain valuable employees.

In most cases induction and deduction operate in tandem. Whether the overall shape of our analysis is primarily inductive or deductive, we must appeal to the rationality of the audience by supporting our views with specific, strong, and novel evidence or with evidence from credible sources. The tangible evidence can not only strongly enhance our credibility and the long-term and immediate persuasiveness of the message, but also be especially helpful to refuting those who are skeptical about our ideas.

In a word, the more compelling our reasoning is, the sounder our ideas will turn out to be and the more convincing our writing will be.

\section{B. Establishing Common Ground with the Audience}

In persuasive writing, a very important step is to identify with the audience, to establish common ground with them and to show them that we share with them their values, attitudes and experiences, which in a sense means making some accommodation before presenting our points of view. But accommodating does not mean catering for the audience's biases or weaknesses. If we only write about something with which our audiences are very familiar without providing any new ideas, we are catering to them and debasing them and ourselves. In this case we are, in fact, assuming that our audiences can be manipulated easily and do not have the intelligence to think for themselves. If so, our writing will for sure antagonize the audiences and consequently make them resist our ideas.

As a matter of fact, accommodating appeals to the audience's legitimate interests and concerns. When we make accommodation, we can say honestly what is in our mind. But we had better express it in such a way that we show regards for their convictions and concerns as well as our own. Even if we disagree with them on certain subjects, we must recognize that some of their opinions may have validity. We should acknowledge the valid part that is consistent with ours and then present our viewpoints on the basis of it, by which we can make our writing more acceptable. Watt's essay "Drug Abuse in the Work Place" (qtd. in Trimmer, 1988) is an excellent example of accommodation. In the essay the author first presents his audience's viewpoint that employers are concerned about "the investments of their stockholders, the safety of their workers, and the credibility of their goods and services" and therefore "favor various forms of urine testing to identify drug abuses." Then he continues to say that the workers are not only concerned about "the integrity of the work place" but also concerned about "their own integrity." However, investigation shows that both pre-employment physical testing and testing when performance is being impaired cannot guarantee the integrity of the work place and that of individual workers. Instead, "the whole procedure, rather than increasing productivity, destroys the mutual trust between employers and workers so essential to quality performance." Then what can be done to satisfy both the employers and the workers? At this moment, the author presents his own idea. It is evident that such accommodation will elicit positive response from the audience and facilitate their approval of the writer's point of view.

\section{Revising for Correctness and for Style}

After we have arrived at a reasonably complete draft, it is time for us to proofread our writing to make sure that it obeys the rules of grammar, punctuation, and spelling, because without correctness our writing is most likely to be unclear and incoherent and as a consequence, it will be unreadable and our credibility with the audience will be severely damaged. In this case, we ourselves inadvertently invite the audience to dismiss us and our writing.

Besides revising for correctness, we also need to create our own writing style. In the words of Rosenwasser and Stephen (2008), "style" refers to "all of a writer's decisions in selecting, arranging, and expressing what he or she has to say." In their opinion, style to a writer is what a chisel to a sculptor. As a sculptor uses a chisel to "bring out" a shape 
from a block of walnut or marble, a writer uses style to bring out the shape of the conceptual connections in a draft of an essay, which requires that we become aware of our words as words and of our sentences as sentences. Many factors, such as our aim and sense of audience, the ways we approach and develop a topic, the kinds of evidence we choose, and, particularly, the kinds of syntax and diction we characteristically select, affect our personal style. The decisions we make about how to phrase our meaning inevitably exert a powerful influence on the meaning we make. When revising for style, we should consciously reorient ourselves towards communicating to our audience the results of the dialogue we have with ourselves about our topic and make careful choices among more or less effective ways of formulating and communicating our meaning.

\section{CONCLUSION}

In conclusion, what has been analyzed above well demonstrates the importance of and the main strategies for establishing a writer's credibility in persuasive writing. Although we cannot use all the strategies in a single piece of writing, we can build up our credibility by effectively employing some of them so as to write clearly and eliminate contradictions within the text itself, or avoid any internal errors in syntax and mechanics as well as any factual errors in the subject matter. In a sense, what we say and how we say it determine the destiny of our writing: a success or a failure. So we should try every possible means, such as exploring a topic earnestly, admitting the valid points of the opposition, providing sufficient evidence, reasoning soundly and observing the writing mechanics, to make our papers appear written by capable and trustworthy people so as to win over the audiences and to achieve our writing purposes.

\section{REFERENCES}

[1] Henning, Martha L. (1998). Friendly Persuasion: Classical Rhetoric--Now! Draft Manuscript. http://www.millikin.edu/wcenter/workshop7b.html (accessed 19/8/2012)

[2] Lucas, Stephen E. (1989). The Art of Public Speaking. 3rd ed. New York: Random House, Inc.

[3] Lucas, Stephen E. (2004). The Art of Public Speaking. 8th ed. Beijing: Foreign Language Teaching and Research Press.

[4] Rosenwasser, David \& Stephen, Jill. (2008). Writing Analytically. 5th ed. Beijing: Peking University Press.

[5] Shi, Jian \& Shuai, Peitian. (2010). English Writing: From Sentence to Paragraph and to Theme. Beijing: Foreign Language Teaching and Research Press.

[6] Shi, Youshan \& Zhang, Longxi. (1989). 100 Famous Speeches. Beijing: China Translation \& Publishing Corporation (CTPC).

[7] Trimmer, Joseph F. \& McCrimmon, James M. (1988). Writing with a Purpose. 9th ed. Boston: Houghton Mifflin Company.

[8] Yang, Xiahua. (1984). Composition and Rhetoric. Anhui: Anhui Educational Publishing House.

[9] Young, Richard E., et al. (1970). Rhetoric: Discovery and Change. New York: Harcourt Brace Jovanovich, Inc.

[10] http://en.wikipedia.org/wiki/Persuasive_writing (accessed 10/2/2014).

Yuru Shen was born in Meishan, China in 1966. She received her master's degree in language and literature from East China Normal University, China in 1998.

She is currently a professor in the School of Foreign Languages, Leshan Normal University, Leshan, China. Her research interests include English pedagogical theory and practice and English writing.

Prof. Shen is a member of the CELEA (China English Language Education Association) Writing Professional Committee. 